\title{
Contactin-Associated Protein (Caspr) and Contactin Form a Complex That Is Targeted to the Paranodal Junctions during Myelination
}

\author{
Jose C. Rios, ${ }^{1}$ Carmen V. Melendez-Vasquez, ${ }^{1}$ Steven Einheber, ${ }^{1}$ Marc Lustig, ${ }^{2}$ Martin Grumet, ${ }^{2}$ \\ John Hemperly, ${ }^{5}$ Elior Peles, ${ }^{6}$ and James L. Salzer ${ }^{1,3,4}$ \\ Departments of ${ }^{1}$ Cell Biology, ${ }^{2}$ Pharmacology, ${ }^{3}$ Neurology, and the ${ }^{4}$ Kaplan Cancer Center, New York University School of \\ Medicine, New York, New York 10016, 5BD Technologies, Research Triangle Park, North Carolina 27709, and ${ }^{6}$ Department \\ of Molecular Cell Biology, The Weizmann Institute of Science, Rehovot 76100, Israel
}

\begin{abstract}
Specialized paranodal junctions form between the axon and the closely apposed paranodal loops of myelinating glia. They are interposed between sodium channels at the nodes of Ranvier and potassium channels in the juxtaparanodal regions; their precise function and molecular composition have been elusive. We previously reported that Caspr (contactin-associated protein) is a major axonal constituent of these junctions (Einheber et al., 1997). We now report that contactin colocalizes and forms a cis complex with Caspr in the paranodes and juxtamesaxon. These proteins coextract and coprecipitate from neurons, myelinating cultures, and myelin preparations enriched in junctional markers; they fractionate on sucrose gradients as a high-molecular-weight complex, suggesting that other proteins may also be associated with this complex. Neurons express two contactin isoforms that differ in their extent of glycosylation: a lower-molecular-weight phosphatidylinositol phospholipase C (PI-PLC)-resistant form is
\end{abstract}

associated specifically with Caspr in the paranodes, whereas a higher-molecular-weight form of contactin, not associated with Caspr, is present in central nodes of Ranvier. These results suggest that the targeting of contactin to different axonal domains may be determined, in part, via its association with Caspr. Treatment of myelinating cocultures of Schwann cells and neurons with RPTP $\beta-F c$, a soluble construct containing the carbonic anhydrase domain of the receptor protein tyrosine phosphatase $\beta$ (RPTP $\beta$ ), a potential glial receptor for contactin, blocks the localization of the Caspr/contactin complex to the paranodes. These results strongly suggest that a preformed complex of Caspr and contactin is targeted to the paranodal junctions via extracellular interactions with myelinating glia.

Key words: myelin; axons; Caspr; contactin; nodes of Ranvier; paranode
Myelinated fibers are organized into distinct domains: the internode, the juxtaparanodal and paranodal regions, and the node of Ranvier (Salzer, 1997). This organization, which is critical for appropriate saltatory conduction, results from poorly understood interactions between axons and Schwann cells in the PNS and oligodendrocytes in the CNS. Each of these domains has a distinct molecular composition and physiological role (Arroyo and Scherer, 2000; Peles and Salzer, 2000). Thus, high concentrations of voltagegated sodium channels and delayed rectifier potassium channels are found in the nodal and juxtaparanodal regions, respectively.

Specialized paranodal junctions (PNJs), which form between the axolemma and the closely apposed paranodal loops of myelinating glia (Peters et al., 1991), are interposed between these channel domains. These junctions have been proposed to anchor myelin loops to the axon, form a partial diff usion barrier into the periaxonal space, and demarcate axonal domains by limiting the lateral

\footnotetext{
Received June 22, 2000; revised Aug. 21, 2000; accepted Aug. 24, 2000.

This work was supported by National Multiple Sclerosis Society Grant RG-3102 and Grant 97-00093 from the United States-Israel Science Foundation (BSF) to E.P., and by Grant NS38208 from the National Institutes of Health (NIH) to J.L.S. J.C.R. is a Medical Scientist Trainee supported by NIH Training Grant 5T32 GM07308 from National Institute of General Medial Sciences. Elior Peles is Incumbent of the Madeleine Haas Russell Career Development Chair. We thank Dr. T. Morimoto and Tian Huan Shen for advice with the sucrose gradient analysis; J. Haspel for providing L1-Fc; Drs. T. Sakurai, S. Lambert, and D. Colman for antibodies; Lee Cohen-Gould for assistance with confocal microscopy; and Drs. G. Fishell, M. Phillips, and Deborah Kittell for the use and assistance with their digital imaging facility.

J.C.R. and C.V.M.-V. contributed equally to the current study.

Correspondence should be addressed to Dr. James L. Salzer, Department of Cell Biology, New York University Medical School, 550 First Avenue, New York, NY 10016. E-mail: Jim.salzer@med.nyu.edu.

Dr. Grumet's present address: Department of Cell Biology and Neuroscience, Keck Center for Collaborative Neuroscience, Rutgers, State University of New Jersey, Piscataway, NJ 08854.

Copyright (C) 2000 Society for Neuroscience $0270-6474 / 00 / 208354-11 \$ 15.00 / 0$
}

diff usion of membrane components (Rosenbluth, 1995). They also represent a potential site for bidirectional signaling between axons and myelinating glia. Evidence for a critical role of the PNJs in organizing these domains has come from studies of galactocerebroside-deficient mice (Coetzee et al., 1996; Bosio et al., 1998). In the PNS of these mice, the transverse bands, which are the hallmark of these junctions, are missing (Dupree et al., 1999). Of note, the distribution of $\mathrm{K}^{+}$channels was perturbed significantly, and the strict separation between $\mathrm{Na}^{+}$and $\mathrm{K}^{+}$channels that is a prominent feature of normal axons was frequently absent.

The first major component of these junctions to be identified was the contactin-associated protein (Caspr), also termed paranodin (Einheber et al., 1997; Menegoz et al., 1997). Caspr was isolated originally on the basis of its copurification with contactin when the carbonic anhydrase domain of the receptor protein tyrosine phosphatase $\beta(\operatorname{RPTP} \beta)$ was used as an affinity ligand (Peles et al., 1997). Caspr is a neuronal transmembrane protein with an $M_{\mathrm{r}}$ of $190 \mathrm{kDa}$ that contains extracellular neurexin-like repeats and potential binding sites for SH3 domains and band 4.1 proteins in its cytoplasmic region (Peles et al., 1997). It is expressed diff usely on unmyelinated axons but becomes localized to the paranodal junctions shortly after the onset of myelination (Einheber et al., 1997). Contactin is a glycosylphosphatidyl inositol (GPI)-anchored member of the immunoglobulin gene superfamily (Ranscht, 1988; Brümmendorf et al., 1989; Gennarini et al., 1989), which promotes neurite outgrowth and fasciculation and possibly synapse formation and maintenance (Faivre-Sarrailh and Rougon, 1997; Berglund et al., 1999). It is expressed by most neurons in the PNS and CNS as well as by mammalian oligodendrocytes (Einheber et al., 1997; Koch et al., 1997), but not by Schwann cells (Einheber et al., 1997). Despite evidence that Caspr and contactin interact laterally in the plasma membrane of neuronal cell lines (Peles et al., 1997), we 
were unable to detect contactin in the paranodes in our previous studies (Einheber et al., 1997).

Using new reagents, we now report that contactin indeed colocalizes and is targeted with Caspr to the paranodes and the juxtamesaxonal spiral. We also show that contactin and Caspr interact laterally, i.e., in cis, and are likely to be targeted to these axonal domains as a complex. Finally, treatment of myelinating cocultures with a soluble RPTP $\beta-F c$ construct, which binds tightly to contactin, blocks the redistribution of Caspr and contactin to the paranodes, suggesting that extracellular interactions regulate their localization.

Portions of this work have appeared in abstract form (MelendezVasquez et al., 1999; Rios et al., 1999).

\section{MATERIALS AND METHODS}

$F c$ fusion proteins. Two $\mathrm{Fc}$ fusion proteins were used in these studies. One contained the carbonic anhydrase domain of RPTP $\beta$ fused to the hinge region of human IgG1-Fc ( $\beta$ C-Fc; Peles et al., 1997); the other consisted of the extracellular domain of human contactin/F3 also fused to the same Fc region (contactin-Fc; Peles et al., 1995). Stably transfected HEK 293 cells secreting either $\beta \mathrm{C}-\mathrm{Fc}$ or contactin-Fc were maintained on media containing DME (Whittaker Bioproducts, Walkersville, MD), 4\% UltraLow IgG fetal bovine serum (FBS; Life Technologies, Gaithersburg, MD), and $2 \mathrm{~mm}$ glutamine. Conditioned media were collected once a week and alkalinized by adding $1 \mathrm{~m}$ HEPES buffer (Life Technologies) at $10 \%$ volume. Fc fusion proteins were collected by using a protein A-agarose column (Roche Molecular Biochemicals, Indianapolis, IN). The column was washed sequentially with $6 \times$ Dulbecco's PBS (dPBS; Life Technologies) plus $0.2 \%$ Triton X-100 (Sigma, St. Louis, MO), followed by $6 \times \mathrm{dPBS}$ and $1 \times$ dPBS. The proteins were eluted off the column with $100 \mathrm{~mm}$ glycine buffer, $\mathrm{pH} 2.8$; individual fractions were neutralized with $2 \mathrm{M}$ HEPES, $\mathrm{pH} 8.5$, at $5 \%$ volume, and the protein levels were assessed by the Bradford method (Bio-Rad, Hercules, CA). Fractions containing Fc proteins were pooled and dialyzed against dPBS; protein quantitation was performed with the BCA Protein Assay (Pierce, Rockford, IL).

Tissue culture methods. Primary rat Schwann cell and dorsal root ganglion (DRG) neuron cultures and myelinating Schwann cell-neuron cocultures were established as described previously (Einheber et al., 1997) with minor modifications. Embryonic day 16-17 (E16-E17) rat DRGs were explanted directly into culture or were trypsinized first (Life Technologies) and dissociated by trituration before being plated onto $12 \mathrm{~mm}$ glass coverslips coated with collagen (Biomedical Technologies, Stoughton, MA). Cultures were maintained in standard neuronal media, which consisted of MEM (Life Technologies) supplemented with 10\% FBS, $2 \mathrm{~mm}$ glutamine, $0.4 \%$ glucose (Sigma), and $50 \mathrm{ng} / \mathrm{ml} 2.5 \mathrm{~S}$ nerve growth factor (NGF; Bioproducts for Science, Indianapolis, IN). During the first 2.5 weeks the cultures were treated with 5-fluorodeoxyuridine and uridine at $10^{-5} \mathrm{M}$ (Sigma) that were added to the standard neuronal media in alternate feedings to eliminate non-neuronal cells.

Schwann cell/neuronal cocultures were prepared by seeding purified DRG explants or dissociated cultures with 200,000 Schwann cells per coverslip in standard neuronal media. The next day the cocultures were fed with N2 media consisting of $5 \mathrm{mg} / \mathrm{ml}$ insulin (Sigma), $10 \mathrm{mg} / \mathrm{ml}$ transferrin (Jackson ImmunoResearch Laboratories, West Grove, PA), 20 nm progesterone (Sigma), $100 \mu \mathrm{M}$ putrescine (Sigma), $30 \mathrm{~nm}$ selenium (Sigma), and 2 mM glutamine in a 1:1 mixture of DME and Ham's F-12 (Life Technologies) supplemented with 2.5S NGF. They were maintained in N2 for 3-4 $\mathrm{d}$ so that the Schwann cells could populate the neurites. To initiate basal lamina formation and myelination, the cocultures were fed standard neuronal media supplemented with $50 \mu \mathrm{g} / \mathrm{ml}$ ascorbic acid (Sigma). For perturbation studies $\beta \mathrm{C}-\mathrm{Fc}$ or human IgG (Jackson ImmunoResearch Laboratories; both at $25 \mu \mathrm{g} / \mathrm{ml}$ or $100 \mu \mathrm{g} / \mathrm{ml}$ ) was added to the myelinating media. After 15 or $21 \mathrm{~d}$ of treatment the cocultures were fixed with $4 \%$ paraformaldehyde and were processed for immunofluorescence.

Preparation of teased sciatic nerves and optic nerve sections. Sciatic nerves were removed from Sprague Dawley rats (Taconic Farms, Germantown, NY) of specified ages and fixed in dPBS with $4 \%$ paraformaldehyde (Fisher Scientific, Springfield, NJ) for $1.5 \mathrm{hr}$ for the nerves from postnatal day $0-4$ rat pups and for $4 \mathrm{hr}$ for the nerves from adults. The nerves were stored in dPBS at $4^{\circ} \mathrm{C}$ until teased. Using fine needles, we teased the individual fibers of the sciatic nerve while they were in ice-cold dPBS. Teased sciatic nerve fibers (TSNs) then were mounted on glass slides and dried overnight at room temperature. The slides were stored at $-80^{\circ} \mathrm{C}$ until they were stained for immunofluorescence. Optic nerves were dissected out and fixed in 4\% paraformaldehyde (Fisher Scientific) in dPBS for 1.5 hr. The nerves were stored in dPBS and then cryoprotected with $30 \%$ sucrose (Sigma). Nerves were frozen with crushed dry ice and stored at $-80^{\circ} \mathrm{C}$. Tissue was mounted with Tissue-Tek OCT (VWR Scientific Products, New York, NY) for cryostat sectioning. Tissue was sectioned at 10 $\mu \mathrm{m}$ on a Leica CM1900 cryostat with a chamber temperature of $-24^{\circ} \mathrm{C}$ and stage temperature of $-26^{\circ} \mathrm{C}$. Sections were stored at $-80^{\circ} \mathrm{C}$ until they were stained for immunofluorescence.

Antibodies and immunofluorescence. For many of these studies we used an affinity-purified rabbit polyclonal antibody generated against human
contactin/F3 (Reid et al., 1994). Rabbit polyclonal antibodies to Caspr (Peles et al., 1997), myelin-associated glycoprotein (MAG; Pedraza et al., 1990), myelin basic protein (MBP; gift of D. Colman, Mount Sinai Medical Center New York, NY), and L1 (Friedlander et al., 1994) and a chicken antibody to ankyrinG (gift of S. Lambert, University of Massachusetts, Worcester, MA) also were used. We also generated a rabbit polyclonal antibody to contactin by immunizing with the contactin-Fc fusion protein described above. The anti-MBP monoclonal antibody SMI 94 (Sternberger Monoclonals, Baltimore, MD) was used to stain myelin segments. Goat secondary antibodies to rabbit or human $\mathrm{IgG}$ conjugated to rhodamine or FITC and goat anti-mouse antibodies conjugated to FITC were purchased from Jackson ImmunoResearch Laboratories; goat secondary antibodies to rabbit or human IgG conjugated to Alexa 594 and to human IgG conjugated to Alexa 488 were purchased from Molecular Probes (Eugene, OR).

Fixed tissue samples (TSNs, optic nerve sections, cocultures, and capped DRG neurons) were permeabilized with acetone at $-20^{\circ} \mathrm{C}$, washed with dPBS, and blocked for $1 \mathrm{hr}$ at room temperature in a blocking solution consisting of dPBS, $5 \%$ BSA, $1 \%$ normal goat serum, and $0.2 \%$ Triton X-100 (Sigma). Primary antibodies diluted in blocking solution were added and left overnight in a humidifying chamber at $4^{\circ} \mathrm{C}$. After being washed several times with dPBS plus $0.2 \%$ Triton $\mathrm{X}-100$, the tissue was incubated with corresponding secondary antibodies at a dilution of 1:100 in blocking solution for $1 \mathrm{hr}$ at room temperature. Then the tissue was washed several times with dPBS, washed once with water, and mounted in Citifluor (Ted Pella, Redding, CA) containing Hoechst nuclear stain. The tissue was examined by epifluorescence on either a Zeiss Axiophot microscope or on a Zeiss LSM 510 confocal microscope.

Cocapping studies. For analysis of protein association by cocapping, DRG neurons were rinsed with dPBS and then incubated with conditioned media collected from $\beta \mathrm{C}-\mathrm{Fc}$-secreting HEK 293 cells (Peles et al., 1995) for $1 \mathrm{hr}$ at $4^{\circ} \mathrm{C}$. Cultures were washed with dPBS for $5 \mathrm{~min}$ at $4^{\circ} \mathrm{C}$ and incubated with Alexa 488-conjugated goat anti-human IgG for $1 \mathrm{hr}$ at $4^{\circ} \mathrm{C}$. Cultures were washed with dPBS and either were fixed directly or were incubated in standard media for an additional $6 \mathrm{hr}$ at $37^{\circ} \mathrm{C}$ and fixed. Then the cultures were stained for contactin, Caspr, or L1 as described above. Isolation of myelin fractions. Myelin was prepared from frozen adult rat brains (Pel-Freez Biologicals, Rogers, AR) according to the method of Norton and Poduslo (1973) with minor modifications. Briefly, five rat brains were homogenized in $170 \mathrm{ml}$ of $0.85 \mathrm{M}$ sucrose in $10 \mathrm{~mm}$ Tris buffer, $\mathrm{pH} 7.4$, containing $2 \mathrm{~mm}$ EDTA and $1 \mathrm{~mm}$ PMSF. The homogenate was transferred to six Nalgene centrifuge tubes (Nalge Nunc, Rochester, NY) and layered with $8 \mathrm{ml}$ of $0.25 \mathrm{M}$ sucrose. The homogenate was centrifuged overnight in a SW28 Beckman rotor (Beckman Instruments, Palo Alto, CA) at $22,500 \mathrm{rpm}$. The crude myelin at the $0.25 / 0.85 \mathrm{M}$ interface was collected and osmotically shocked by washing with 10 vol of distilled water. Myelin subfractions were obtained by subjecting the initial myelin preparation to a second discontinuous sucrose gradient consisting of $15 \mathrm{ml}$ of $0.62 \mathrm{M}$ sucrose layered over $15 \mathrm{ml}$ of $0.70 \mathrm{M}$ sucrose (Matthieu et al., 1973). After centrifugation at $67,000 \times g$ for $30-45 \mathrm{~min}$, three fractions were collected: material less dense than $0.62 \mathrm{~m}$ sucrose (light myelin), material within the $0.62-0.70 \mathrm{~m}$ layer (medium myelin), and the pellet (heavy myelin). The starting myelin preparation and the myelin subfractions were washed with Tris-EDTA buffer and kept at $-80^{\circ} \mathrm{C}$ until required.

Myelin was prepared from the PNS by grinding 25 frozen rat sciatic nerves (Pel-Freez Biologicals) in a ceramic mortar cooled with liquid nitrogen (Greenfield et al., 1973). The nerve powder was collected and homogenized in $10 \mathrm{ml}$ of $0.32 \mathrm{M}$ sucrose in Tris-EDTA buffer. The homogenate was filtered through a $200 \mu \mathrm{m}$ nylon mesh to remove the bulk of the collagen and layered at the top of a centrifuge tube containing 0.9 $\mathrm{M}$ sucrose. Tubes were spun overnight at 22,500 rpm in a SW28 rotor (Beckman Instruments), and the myelin migrating at the $0.32 / 0.9 \mathrm{~m}$ sucrose interface was collected, washed, and kept at $-80^{\circ} \mathrm{C}$ until further use.

Detergent solubilization. Unfractionated myelin and myelin subfractions (1 $\mathrm{mg}$ total protein) were extracted with $1 \mathrm{ml}$ of a detergent solution prepared in Tris buffer (10 mM, pH 7.4), containing $10 \mathrm{~mm}$ EDTA, $1 \mathrm{~mm}$ PMSF, $10 \mu \mathrm{g} / \mathrm{ml}$ aprotinin, and $20 \mu \mathrm{M}$ leupeptin with or without $500 \mathrm{~mm}$ $\mathrm{NaCl}$. The following detergents and concentrations were used: $1 \%$ Triton X-100, $60 \mathrm{~mm}$ octyl glucoside, 1\% SDS (Sigma), 0.9\% Zwittergent 3-14 (ZW 3-14; Calbiochem, La Jolla, CA), and 2\% sucrose monolaurate (Roche Molecular Biochemicals). Samples were incubated for $1 \mathrm{hr}$ at $4^{\circ} \mathrm{C}$ with constant agitation, except for SDS extractions that were performed at room temperature for 30 min only. Detergent-soluble (supernatants) and insoluble fractions (pellets) were separated by centrif ugation at $12,000 \times$ $g$ for $10 \mathrm{~min}$ in a Marathon 13K/M microcentrif uge (Fisher Scientific) and analyzed by Western blotting. Detergent extracts also were prepared from primary cultures of DRG neurons and myelinating cocultures following the protocol described above.

Sucrose gradient analysis. Supernatants from detergent extracts were subjected to sucrose density gradient centrifugation to estimate the molecular size of solubilized Caspr and contactin (Martin and Ames, 1961). Briefly, $0.25-1 \mathrm{ml}$ of extracts were layered on top of $11 \mathrm{ml}$ of a continuous $10-45 \%$ sucrose gradient made up in Tris-EDTA buffer, $\mathrm{pH} 7.4(10 \mathrm{mM}$ Tris, $10 \mathrm{~mm}$ EDTA). Samples were centrifuged for $20 \mathrm{hr}$ at 35,000 rpm in a Beckman SW41 rotor (Beckman Instruments). Fractions of $1 \mathrm{ml}$ were harvested from the top, and their density was determined by measurement of the refractive index. The protein composition of each fraction was 

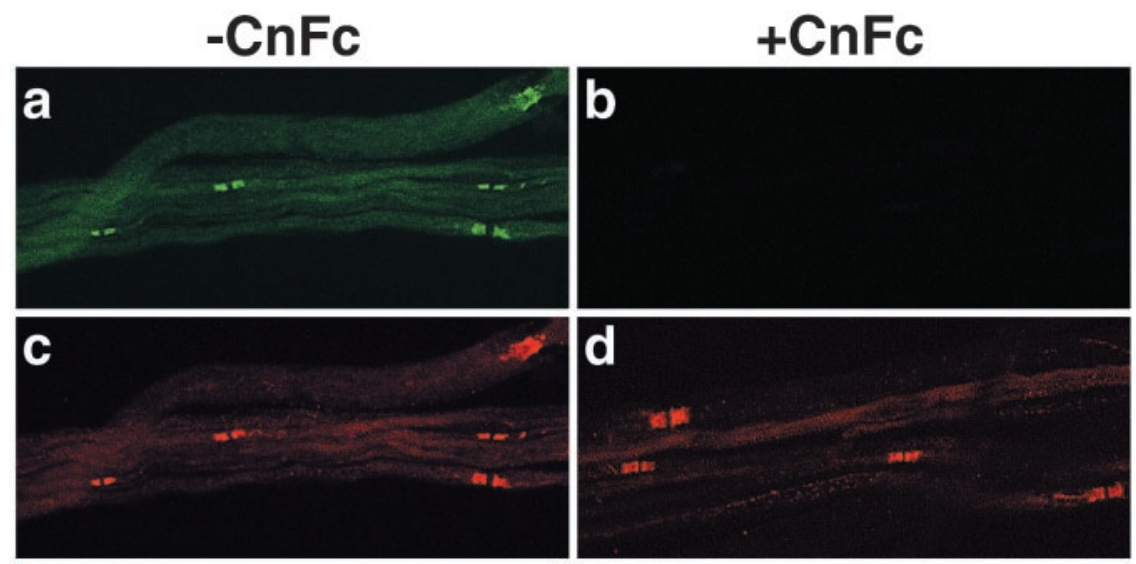

Figure 1. Contactin expression in the paranodes and juxtamesaxonal spiral. Top Panels, Teased fibers from adult rat sciatic nerves were stained with $\beta \mathrm{C}-\mathrm{Fc}$ (fluorescein secondary) and with antibodies to Caspr (rhodamine secondary) either directly $(a, c, e)$ or after preincubation of these reagents with contactin-Fc $(b$, $d, f) . \beta C-\mathrm{Fc}(a)$ and Caspr antibodies $(c)$ both stain the paranodes and colocalize in the merged image $(e)$. The staining of $\beta \mathrm{C}-\mathrm{Fc}$ is specific for contactin because preincubation with contactin-Fc eliminated all staining $(b)$ without affecting Caspr labeling $(d)$; the merged image is shown in $f$. Bottom panels, Higher magnification of the paranodal region shows colocalization of contactin, stained with $\beta \mathrm{C}-\mathrm{Fc}$ and $\mathrm{Caspr}$ in the paranodes and in the juxtamesaxonal spiral in a merged confocal image $\left(a^{\prime}\right)$. Staining with an affinitypurified antibody against contactin $\left(b^{\prime}\right)$ similarly demonstrates paranodal and juxtamesaxonal staining. Scale bars: $a-f, 20 \mu \mathrm{m} ; \mathrm{a}^{\prime}, \mathrm{b}^{\prime}, 10 \mu \mathrm{m}$.
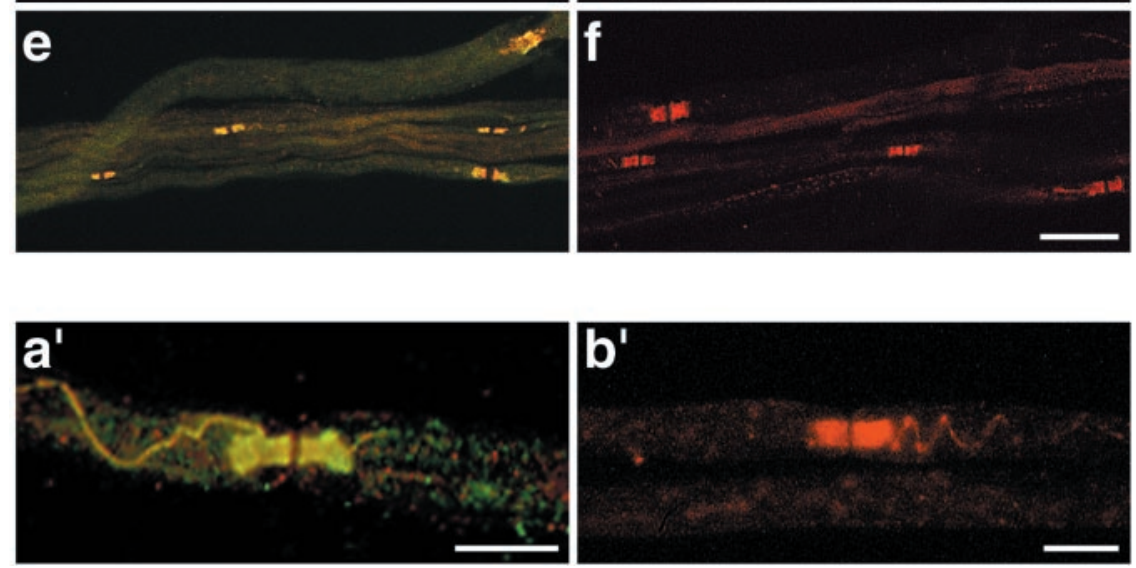

analyzed by SDS-PAGE and Western blotting. Molecular weight standards (Sigma) consisting of bovine thyroglobulin $(669 \mathrm{kDa})$, horse apoferritin $(443 \mathrm{kDa})$, and bovine gamma globulin $(150 \mathrm{kDa})$ were analyzed in parallel.

Metabolic labeling and immunoprecipitation. DRG neurons and myelinating cocultures were rinsed with methionine-free DMEM (Life Technologies). Cultures were labeled for 16-18 hr with DMEM containing 250 $\mu \mathrm{Ci} / \mathrm{ml}\left[{ }^{35} \mathrm{~S}\right] \mathrm{methionine}$ (Trans ${ }^{35} \mathrm{~S}-\mathrm{Label}$, ICN Biomedicals, Costa Mesa, $\mathrm{CA})$. At the end of the labeling period the radioactive medium was removed, and the cultures were chased for $2 \mathrm{hr}$ in complete DMEM (Life Technologies). Cultures were washed three times with PBS and extracted with detergents as described above. One set of neuron cultures was treated with $1 \mathrm{U} / \mathrm{ml}$ of phosphatidylinositol phospholipase C (PI-PLC; Sigma) for $1 \mathrm{hr}$ at $37^{\circ} \mathrm{C}$ before detergent extraction and immunoprecipitation. Cell detergent extracts were diluted two to four times with Tris-EDTA buffer, $\mathrm{pH} 7.4$ (10 mM Tris, $10 \mathrm{~mm}$ EDTA) and precleared for $1 \mathrm{hr}$ with protein-A agarose. For SDS extracts, the dilution buffer included $2 \%$ Triton X-100. Extracts then were incubated for $2 \mathrm{hr}$ at $4^{\circ} \mathrm{C}$ with Caspr, contactin, or preimmune serum or with protein A-agarose beads coupled to $\mathrm{RPTP} \beta \mathrm{C}-\mathrm{Fc}$ fusion protein. For $\mathrm{Caspr}$, contactin, and preimmune serum immunoprecipitations, protein-A beads were added after antibody incubation. Beads were collected by centrifugation and washed four to five times with Tris-EDTA buffer containing the detergent used for solubilization. After the last wash, consisting only of Tris-EDTA buffer, the beads were boiled for $3 \mathrm{~min}$ in SDS sample buffer. Immunoprecipitates were fractionated by SDS-PAGE and analyzed by autoradiography with a PhosphorImager (Molecular Dynamics, Sunnyvale, CA).

In other studies, ZW 3-14 extracts of heavy myelin fractions were incubated for $2 \mathrm{hr}$ with RPTP $\beta \mathrm{C}-\mathrm{Fc}$ fusion protein coupled to $\mathrm{CNBr}$ Sepharose (Amersham Pharmacia Biotech, Piscataway, NJ). Beads were washed four to five times with $0.09 \%$ ZW 3-14 in Tris-EDTA buffer, $\mathrm{pH}$ 7.4 (10 mM Tris, $10 \mathrm{~mm}$ EDTA) and boiled in SDS sample buffer. Precipitates from heavy myelin were separated by SDS-PAGE and analyzed by silver staining (Silver SNAP Stain, Pierce) and Western blotting. Blots were developed using the SuperSignal chemiluminescent substrate (Pierce).

Surface biotinylation and enzymatic deglycosylation. Cultures of DRG neurons were washed two times, for 5 min each, with ice-cold PBS and then biotinylated with $0.5 \mathrm{mg} / \mathrm{ml}$ of sulfo-NHS-LC-biotin (Pierce) for $30 \mathrm{~min}$ at $4^{\circ} \mathrm{C}$. Cells were washed two times for $10 \mathrm{~min}$ with Leibovitz's L- 15 medium (Life Technologies) to quench unreacted biotin and then with ice-cold PBS. Biotinylated cultures were lysed in 0.9\% ZW 3-14 and subjected to immunoprecipitation with anti-contactin antibodies as described above. Contactin immunoprecipitates were denatured by boiling in $0.5 \%$ SDS and $1 \% \beta$-mercaptoethanol for $10 \mathrm{~min}$ and then treated with $12,500 \mathrm{U} / \mathrm{ml}$
PNGase F (New England Biolabs, Beverly, MA) for $1 \mathrm{hr}$ at $37^{\circ} \mathrm{C}$ in buffer containing $1 \%$ NP-40. The reaction was stopped by adding SDS-PAGE sample buffer. Immunoprecipitates treated in parallel without enzyme served as a control. Samples were separated by SDS-PAGE and analyzed by Western blotting. Blots were developed using streptavidin-peroxidase (Jackson ImmunoResearch Laboratories) and the SuperSignal chemiluminescent substrate (Pierce).

Analysis of $\beta C-F c$-treated cultures. The distribution of Caspr in control and $\beta \mathrm{C}-\mathrm{Fc}$-treated cultures $(25$ and $100 \mu \mathrm{g} / \mathrm{ml})$ was determined in both explant and dissociated neuron-Schwann cell cocultures; similar results were observed in each type of culture. Quantitation of three separate experiments was performed by counting from photomicrographs of high power $(400 \times)$ fields or, in the case of explant cultures, quantifying the Caspr-staining pattern of MBP-positive segments throughout the entire coverslip. Over 500 paranodes were analyzed for each $\beta \mathrm{C}-\mathrm{Fc}$ concentration.

\section{RESULTS}

\section{Colocalization of contactin and Caspr at the paranode in vivo and in vitro}

In previous studies we reported that, although Caspr and contactin can be detected by Western blot analysis after myelination in vivo and in vitro, only Caspr was detected at the paranodes (Einheber et al., 1997). We have reexamined the distribution of contactin in myelinated axons by using additional reagents: rabbit polyclonal antibodies, generated against affinity-purified contactin (Reid et al., 1994) or contactin-Fc, and the RPTP $\beta C-F c(\beta C-F c)$ fusion protein (Peles et al., 1995).

Staining of adult teased sciatic nerves (TSNs) with these reagents demonstrated abundant expression of contactin in the paranodes (Fig. 1). $\beta \mathrm{C}-\mathrm{Fc}$ labeled the paranodes and a thin spiral extending into the internode (Fig. 1a, $a^{\prime}$ ). Double staining with MAG antibodies (data not shown) confirmed that this staining apposes the Schwann cell mesaxon; consequently, we refer to this domain as the juxtamesaxon. An identical staining pattern in the paranodes and juxtamesaxon also was seen with polyclonal antibodies raised against affinity-purified contactin (Fig. $1 b^{\prime}$ ) or contactin-Fc (data not shown). Staining with $\beta \mathrm{C}-\mathrm{Fc}$ was specific for contactin because it could be blocked by preincubating with contactin-Fc $(\mathrm{Cn}-\mathrm{Fc}$; 

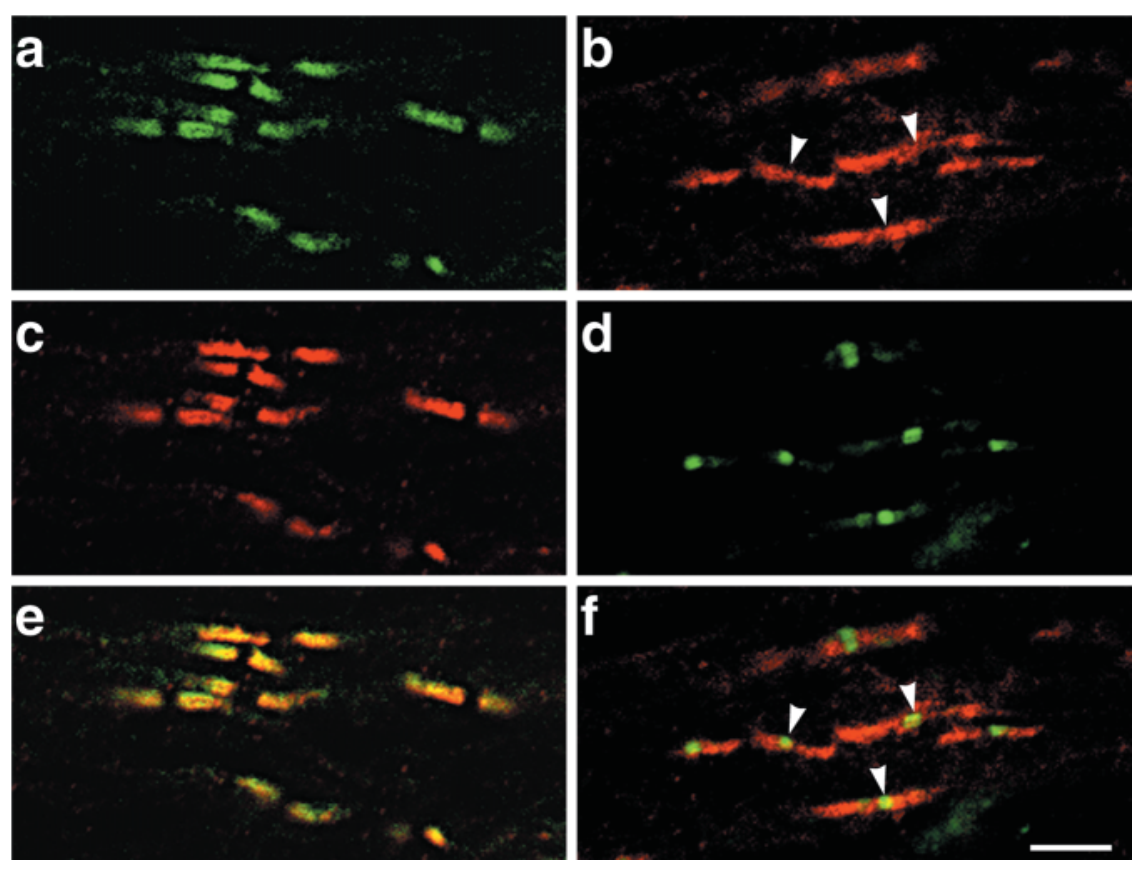

Figure 2. Contactin is localized in the paranodes and nodes in the optic nerve. Staining of contactin with $\beta \mathrm{C}-\mathrm{Fc}(a)$ and an anti-Caspr antibody $(c)$ demonstrated specific colocalization of these proteins at the paranodes (merged in $e$ ). Staining with an affinitypurified anti-contactin antibody $(b)$ demonstrates that contactin in the paranodes frequently extends through the nodes of Ranvier; an antibody to ankyrinG $(d)$ identifies the nodes in the same field. In the merged images $(f)$, contactin that is colocalized with ankyring at the node appears yellow; nodes in which contactin is readily visible are indicated by the white arrowheads. Scale bar, $5 \mu \mathrm{m}$.
Fig. $1 b, f)$. Caspr and contactin precisely colocalize in the paranodes and the juxtamesaxon, as illustrated in the merged images of TSNs double-labeled with anti-Caspr antibodies and $\beta \mathrm{C}-\mathrm{Fc}$ (Fig. $\left.1 e, a^{\prime}\right)$. The distribution of contactin in myelinating fibers in the DRG neuron/Schwann cell cocultures was similar to that in the TSNs, with significant levels in the paranodes and minimal expression in the internodes (data not shown). Labeling of the juxtamesaxon was infrequent in the cocultures.

Next, we examined contactin distribution in CNS myelinated fibers (Fig. 2). Frozen sections of optic nerve were stained with $\beta \mathrm{C}-\mathrm{Fc}$ (Fig. $2 a$ ) and antibodies to Caspr (Fig. $2 c$ ), followed by fluorescein- and rhodamine-conjugated secondary antibodies, respectively. As evident by confocal microscopy, both reagents exclusively stained the paranodes (shown merged in Fig. 2e). Again, the $\beta \mathrm{C}-\mathrm{Fc}$ staining was specific for contactin, because it could be blocked completely by preincubation with contactin-Fc (data not shown). In comparison to the PNS, CNS axons were of smaller diameter, and their nodal and paranodal regions were longer relative to their diameter. Antibodies to contactin itself also stained the paranodes (Fig. 2b). Of note, and in contrast to the PNS, this staining extended through the nodal region of many optic nerve fibers, as identified with antibodies to ankyrinG. Overlap of contactin and ankyrin is evident at several nodes (indicated by arrowheads in Fig. $2 b, f)$. In addition, staining with this contactin antibody was present diffusely around some optic nerve fibers, possibly representing oligodendrocyte plasma membranes (data not shown). These results suggest that $\beta \mathrm{C}-\mathrm{Fc}$ preferentially recognizes the Caspr/contactin complex (see below), which is exclusively present in the paranodes, whereas the anti-contactin antibody recognizes contactin in the nodes, paranodes, and possibly on oligodendrocyte membranes.

\section{Developmental time course of contactin and Caspr accumulation at the paranodes}

To determine whether contactin and Caspr accumulate in the paranodal region simultaneously, we analyzed the expression of these proteins in sciatic nerves of rats at postnatal day $0(\mathrm{P} 0), \mathrm{P} 2$, and $\mathrm{P} 4$. We compared staining for Caspr and contactin with that of MBP, a marker of compact myelin (Fig. 3). At P0, only a few MBP-positive myelin segments were present, and staining for both contactin and Caspr was diff use even at the prospective paranodes adjacent to these MBP-positive segments. By P2, the number of MBP-positive segments had increased significantly, and contactin and Caspr were both present in many of the associated paranodes.
The Caspr staining was typically more intense at this stage, possibly reflecting differences in the affinity of these antibodies. Both proteins were most highly concentrated adjacent to the nodes, consistent with the pattern of paranodal junction formation, which begins closest to the node and progresses inward (Tao-Cheng and Rosenbluth, 1983). In unmyelinated axons, Caspr and contactin remained diffuse. By $\mathrm{P} 4$, myelin segments were abundant, and essentially every paranode was strongly positive for both contactin and Caspr. Interestingly, the levels of both proteins were reduced significantly in the corresponding internodes, consistent with findings in the myelinating cocultures. These results indicate that contactin and Caspr accumulate in the paranodes shortly after the onset of myelination and suggest they may be targeted to the paranodes as a complex.

\section{Caspr and contactin cofractionate and coextract from an enriched preparation of paranodal junctions}

We next examined whether Caspr and contactin interact laterally, i.e., in cis, in the paranodes. Because Caspr and contactin are also present at significant levels in gray matter (Einheber et al., 1997; Menegoz et al., 1997), in addition to their localization in the paranodal junctions, we first prepared membrane fractions enriched in these junctions. To this end we prepared crude myelin fractions from rat brain, which are known to contain axolemma, trapped axoplasm, and periaxonal glial membranes in addition to compact myelin (Norton and Cammer, 1984). We separated these preparations into light (enriched in compact myelin), medium, and heavy (enriched in axolemma and glial membranes) fractions by sucrose gradient centrif ugation (Matthieu et al., 1973). Finally, we determined the amount of Caspr, contactin, and MBP in each fraction. Results, shown in Figure $4 A$, demonstrate that $\mathrm{Caspr}$ and contactin are enriched substantially in the heavy myelin fraction; there was a similar enrichment of MAG in these fractions (data not shown). MBP demonstrates a more uniform distribution; in some studies MBP was mainly present in the light fractions. These results indicate that the heavy myelin fraction is enriched in paranodal junctions. It also suggests that the contactin expressed by oligodendrocytes (Einheber et al., 1997; Koch et al., 1997) is unlikely to be present in compact myelin because it could not be detected in the light myelin fraction.

We next analyzed whether Caspr and contactin coextracted from the heavy myelin preparation. Previously, we reported that Caspr was poorly extracted from crude brain membrane preparations by a variety of nonionic detergents, including Triton X-100 (Einheber 


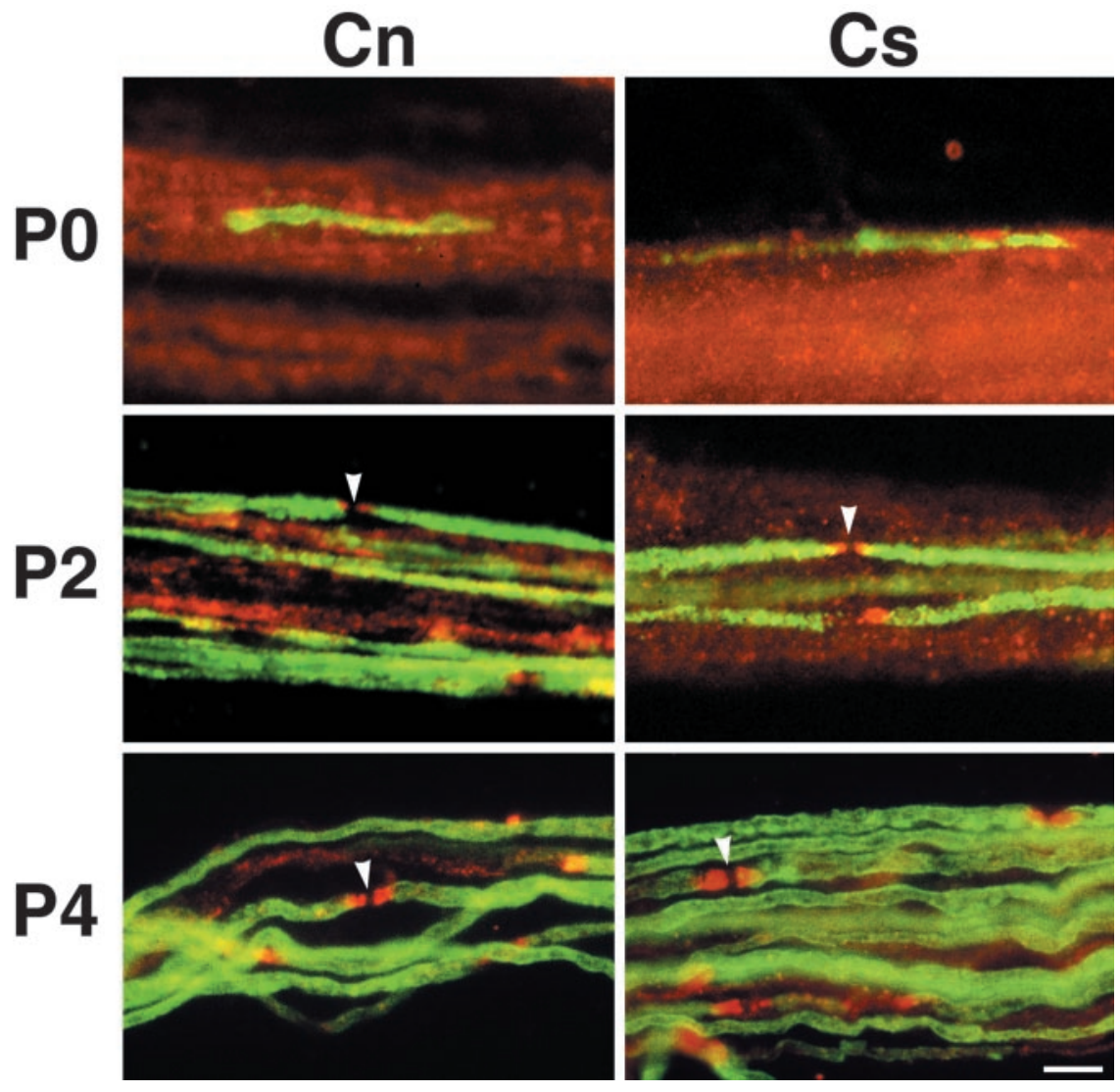

Figure 3. Time course of contactin and Caspr accumulation in the paranodes. Sciatic nerves were removed on P0, P2, and P4, teased, and stained for MBP (fluorescein) and either contactin $(\mathrm{Cn})$ or Caspr (Cs; rhodamine). At P0, few myelin segments have formed, and contactin and Caspr are distributed diffusely on axons. At P2, the number of myelin segments and nodes of Ranvier (white arrowheads) increased significantly, and the first clusters of contactin and Caspr at the paranodes are apparent; the level of contactin at the paranode appears to be less than that of Caspr. By P4, substantial numbers of myelin segments have formed, and contactin and Caspr are highly concentrated in the paranodes. Scale bar, $10 \mu \mathrm{m}$.

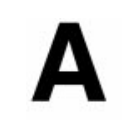

$\begin{array}{cccc}\text { Crude } & \text { Light } & \text { Medium } & \text { Heavy } \\ \text { Myelin } & \text { Myelin } & \text { Myelin } & \text { Myelin }\end{array}$

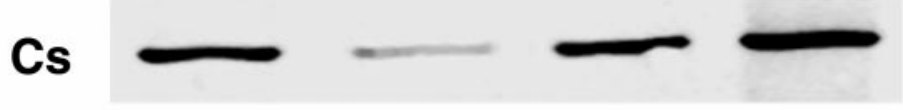

Cn

Figure 4. Caspr and contactin cofractionate and coextract from myelin fractions. Western blot analysis of Caspr and contactin in myelin fractions and detergent extracts is shown. $A$, Crude myelin preparations from rat brain homogenates are separated further into light, medium, and heavy myelin fractions. The heavy myelin fraction, which contains axonal and glial membranes, is enriched in paranodal junctions, as indicated by the increased concentration of Caspr $(C s)$. Contactin $(\mathrm{Cn})$ is also enriched in this fraction, whereas myelin basic protein $(M B P)$ is found in all of the fractions. Each lane was loaded with $50 \mu \mathrm{g}$ of total protein. $B$, Detergent extracts were prepared from heavy myelin membranes, and the supernatant $(S)$ and insoluble pellet $(P)$ were evaluated for the presence of Caspr and contactin. The distribution of myelinassociated glycoprotein $(M A G)$, a protein not found at the paranodal junctions, was also examined. Caspr and contactin can be solubilized from a heavy myelin preparation by sucrose monolaurate $(S M L)$ and Zwittergent 3-14 ( $Z W$ 3-14) with or without $0.5 \mathrm{M} \mathrm{NaCl}$. In the absence of salt Caspr and contactin, but very little MAG, are extracted by ZW 3-14. In contrast, Triton $\mathrm{X}-100$ solubilizes most of the MAG $\left(S_{T X}\right)$, whereas Caspr and contactin are mainly insoluble. These two proteins could then be coextracted by ZW 3-14 from the Triton-insoluble pellet $\left(S_{Z W}\right)$. 


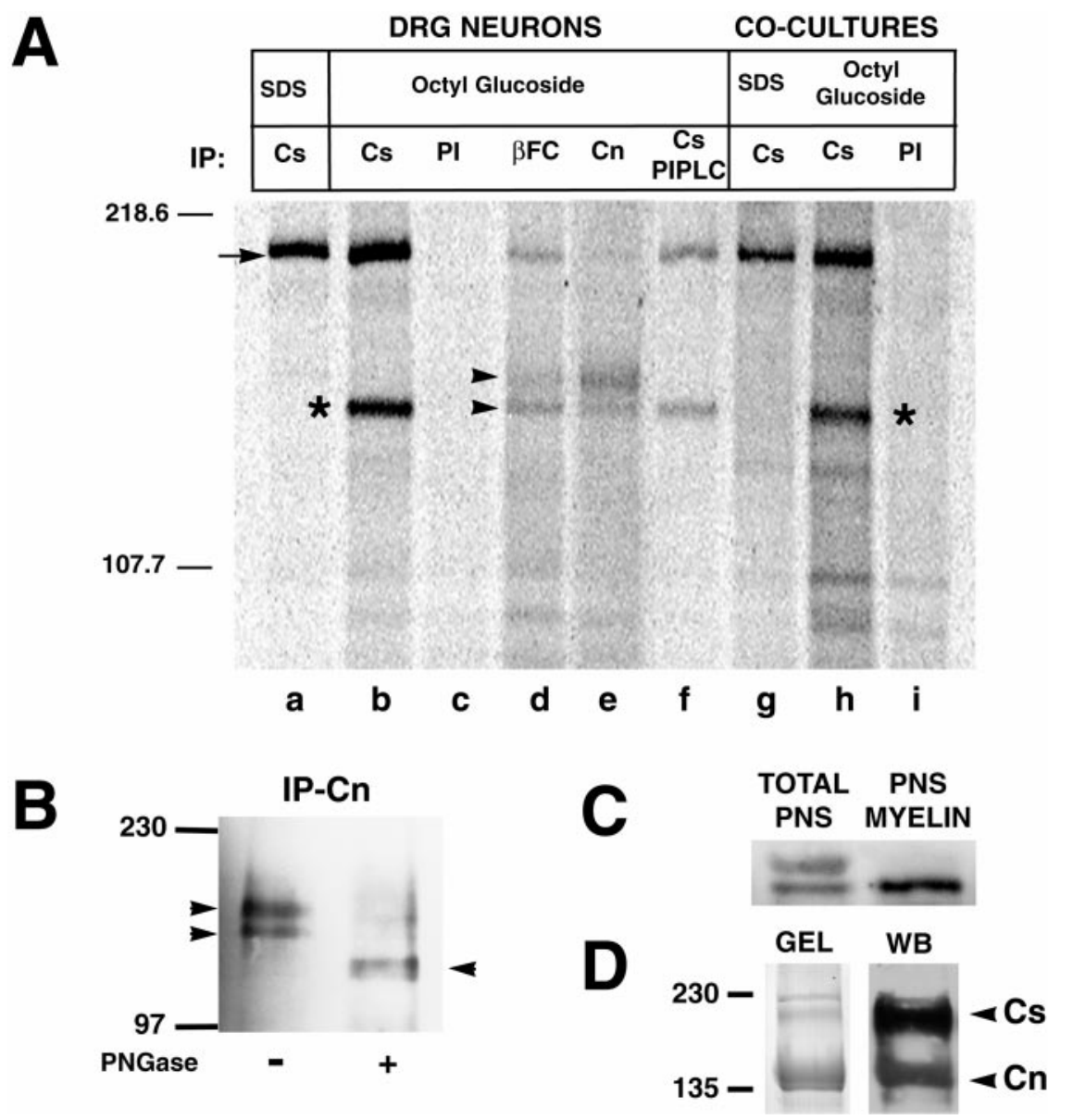

Figure 5. Caspr is complexed with a lower-molecularweight isoform of contactin. $A$, Detergent extracts (1\% $\mathrm{SDS}$ and $60 \mathrm{~mm}$ octyl glucoside) from $\left[{ }^{35} \mathrm{~S}\right] \mathrm{methionine-}$ labeled neuron and myelinating cocultures were subjected to immunoprecipitation with anti-Caspr serum (lanes $a, b, f, g, h)$, control preimmune $(P I)$ serum (lanes $c, i$ ), anti-contactin serum (lane $e$ ), and the fusion protein $\beta \mathrm{C}-\mathrm{Fc}$ (lane $d$ ). The autoradiogram shows a band migrating at $\sim 190 \mathrm{kDa}$ (arrow) immunoprecipitated by anti-Caspr antibodies, both from DRG (lanes $a, b)$ and myelinating cocultures (lanes $g, h$ ). Another protein with an $M_{\mathrm{r}} \sim 135 \mathrm{kDa}$ (asterisk) was coimmunoprecipitated by the Caspr antiserum from octyl glucoside extracts of DRG and myelinating cocultures (lanes $b, h$ ), but not from SDS extracts (lanes $a, g$ ). This band was identified as contactin by parallel immunoprecipitation with $\beta \mathrm{C}-\mathrm{Fc}$ (lane $d$ ) and contactin antiserum (lane e). Two isoforms of contactin (arrowheads) were immunoprecipitated from neurons, but only the lower-molecular-weight PI-PLC-resistant isoform coimmunoprecipitates with Caspr (lane $f$ ). B, Immunoprecipitates of contactin from biotinylated DRG neurons were fractionated and analyzed by Western blotting with streptavidin-peroxidase. Immunoprecipitates were run on gels directly or were pretreated with PNGase F; the two bands present in the untreated sample (arrowheads) resolve as a major band (arrowhead) after treatment. $C$, Western blot of total homogenate and a myelin fraction prepared from sciatic nerve probed with anti-contactin antibodies. $D, \mathrm{ZW}$ 3-14 detergent extracts from heavy myelin were incubated with $\beta \mathrm{C}-\mathrm{Fc}$ that was coupled to Sepharose beads. Material bound to the beads was eluted and analyzed by SDS-PAGE and Western blotting. The silver-stained gel (left) and corresponding immunoblot (right) demonstrate that Caspr $(C s)$ and contactin $(C n)$ elute as part of a complex. Western blots were developed sequentially with each antibody to demonstrate the specificity of the staining; molecular weight markers are indicated on the left. et al., 1997). In the current studies we used sucrose monolaurate (SML) and ZW 3-14. Both detergents effectively solubilized Caspr and contactin from heavy myelin fractions with or without salt (Fig. $4 B$ ). Interestingly, when extractions were performed with ZW 3-14 in the absence of salt, most of the Caspr and contactin were extracted whereas MAG was not. Conversely, Triton X-100 extracted $\sim 80 \%$ of the total protein present in the heavy myelin fraction, including most of the MAG, but Caspr and contactin were mainly insoluble, consistent with previous studies (Einheber et al., 1997). These two proteins could then be coextracted by ZW 3-14 from the Triton-insoluble pellet. Taken together, the cofractionation and cosolubilization of Caspr and contactin from heavy myelin fractions provide further support for an interaction of these proteins in the paranodal junctions.

\section{Caspr is associated with a PI-PLC-resistant form of contactin}

To investigate whether Caspr is associated directly with contactin before and after myelination, we performed a series of immunoprecipitations from SDS or nonionic detergent extracts of metabolically labeled neuron cultures or myelinating cocultures (Fig. 5). Labeled proteins were collected with antibodies to Caspr or contactin or with the $\beta \mathrm{C}-\mathrm{Fc}$ construct, fractionated by SDS PAGE, and analyzed with the PhosphorImager. As expected, a protein with an $M_{\mathrm{r}}$ of $\sim 190 \mathrm{kDa}$ was immunoprecipitated consistently from SDS detergent lysates of both neurons and cocultures with antibodies to Caspr (see Fig. $5 A$, lanes $a, g$ ). Immunoprecipitation of Caspr from nonionic detergent extracts of neurons and myelinating cocultures also brought down approximately equivalent amounts of a $135 \mathrm{kDa}$ protein, confirmed as contactin by parallel immunoprecipitation (Fig. $5 A$, lanes $b, h$ ). Similar immunoprecipitation results were obtained when neurons and cocultures were extracted with SML or ZW 3-14. In the case of ZW 3-14 the interaction between Caspr and contactin was disrupted in the presence of $500 \mathrm{~mm}$
$\mathrm{NaCl}$, indicating that these two proteins are associated via noncovalent, ionic interactions (data not shown).

Of note, contactin antibodies and $\beta \mathrm{C}-\mathrm{Fc}$ each precipitated two isoforms of contactin (Fig. $5 A$, lanes $d, e$ ), consistent with our previous reports that DRGs express two contactin isoforms (Rosen et al., 1992). Of particular interest, only the lower contactin isoform coimmunoprecipitated with Caspr (indicated with an asterisk in lanes $b, h$, Fig. 5A). In addition, treatment with PI-PLC did not affect the association of Caspr with this lower-molecular-weight contactin isoform (Fig. $5 A$, lane $f$ ). We had previously shown that the upper, but not the lower, contactin isoform was released from DRG neurons with PI-PLC treatment (Rosen et al., 1992). These results suggest that the Caspr-associated isoform either is resistant to PI-PLC activity or, if it is cleaved, remains at the cell surface because of its interaction with Caspr.

Both of these isoforms are expressed at the cell surface because they are labeled by external biotinylation (Fig. $5 B$ ). To investigate further the nature of the molecular weight difference between the two contactin isoforms, we treated immunoprecipitates of contactin with PNGase F to remove N-linked carbohydrates. After deglycosylation these two contactin isoforms resolve as a major band with an $M_{\mathrm{r}}$ of $\sim 120 \mathrm{kDa}$, indicating that they differ in the extent of their glycosylation (indicated with an arrowhead, Fig. $5 B$ ); a minor band with a slightly lower $M_{\mathrm{r}}$ may also be present.

To investigate the distribution of these isoforms in vivo, we examined their expression in adult sciatic nerve, which contains both myelinated and nonmyelinated axons. Both isoforms are detectable in Western blots of sciatic nerve homogenates (Fig. 5C), whereas only the lower isoform is detected in myelin fractions prepared from these nerves. Similarly, the lower isoform was coextracted selectively with Caspr by SML and ZW 3-14 (data not shown). These results demonstrate that the lower contactin isoform predominates in myelinated nerves and, together with the immu- 
A

\section{Fraction number}

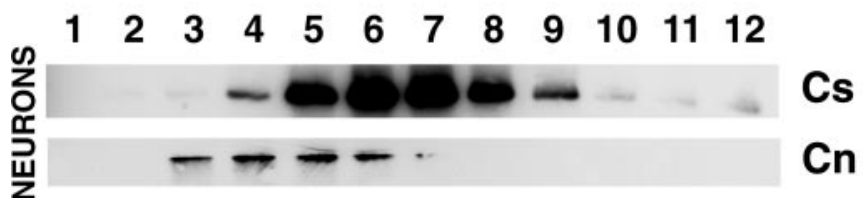

B

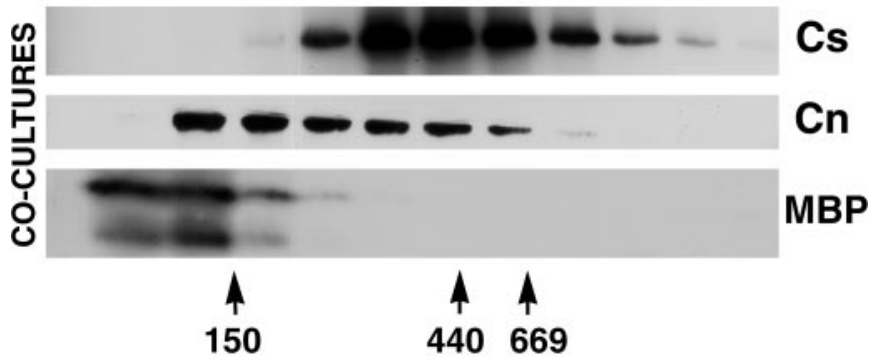

Figure 6. Sucrose gradient analysis of Caspr and contactin from detergent extracts. Sucrose monolaurate extracts of DRG neuron $(A)$ and myelinating cocultures $(B)$ were separated by centrifugation on a $10-45 \%$ sucrose gradient. The $1 \mathrm{ml}$ fractions were collected from the top of the gradient (fraction number 1) down to the bottom (fraction number 12). Aliquots of $100 \mu \mathrm{l}$ were taken from each fraction and evaluated by Western blotting for the presence of Caspr $(C s)$, contactin $(C n)$, and myelin basic protein $(M B P)$. Caspr migrates with an average molecular weight of $550 \mathrm{kDa}$, with significant amounts at much higher sizes, suggesting that it is part of a larger complex; the size of this complex varies slightly from neurons to cocultures. Contactin colocalizes with Caspr mainly in fractions 4-7 in gradients prepared from neurons $(A)$ and in fractions 5-8 in gradients from myelinating cocultures $(B)$. A subpopulation of contactin, not associated with Caspr, was recovered in the low-density fractions (fraction 3). As a control the bottom panel shows the migration of MBP, a protein from compact myelin, which was recovered mostly in fractions $2-4$. The migration of several molecular weight markers run in parallel, including gamma globulin $(150 \mathrm{kDa})$, apoferritin $(440 \mathrm{kDa})$, and thyroglobulin $(669 \mathrm{kDa})$, is indicated at the bottom of the panel (arrows).

nofluorescence studies, indicate that it is localized specifically in the paranodes with Caspr.

Of additional interest, the $\beta \mathrm{C}-\mathrm{Fc}$ appears to immunoprecipitate preferentially the complex of Caspr and the smaller isoform of contactin from neurons, whereas the contactin antibody recognized both isoforms with a preference for the larger isoform (compare lanes $d$, $e$, Fig. 5A). These latter results are consistent with the distinct staining patterns of optic nerve by these two reagents as noted above (see Fig. 2). As shown in Figure $5 D, \beta \mathrm{C}-\mathrm{Fc}$ also efficiently isolates a complex of Caspr and contactin from detergent extracts of the heavy myelin fraction, further supporting their association in this paranode-enriched fraction. The relative excess of contactin visible on the gel is likely to reflect the presence of oligodendrocyte membranes in this fraction that contain contactin, but not Caspr.

\section{Caspr and a subpopulation of contactin migrate at high molecular weights}

To characterize this junctional complex further, Caspr-enriched detergent extracts were sized on sucrose density gradients. SML extracts of DRG neurons and of myelinating cocultures were centrifuged and the distribution of Caspr, contactin, and, in the case of myelinating cocultures, MBP were analyzed (Fig. 6). In both extracts, Caspr migrated at $\sim 550 \mathrm{kDa}$, which was recovered mainly in fractions corresponding to $23-36 \%$ sucrose. This is significantly $>330 \mathrm{kDa}$, the expected molecular weight for a Caspr-contactin dimer. A significant portion of Caspr (30\%), but not contactin, was also detected in the very high-density fractions near the bottom of both gradients. The recovery of Caspr in the heavier fractions of
DRG neuron extracts suggests that it is in larger complexes even before myelination. Its migration in these heavier fractions independently of contactin may also indicate that SML, which efficiently solubilizes both proteins (Peles et al., 1997), partially disrupted their interactions.

Contactin consistently migrated over a lower range of molecular weights; it migrated with Caspr in some, but not all, of the fractions recovered from the gradient. Based on the migration of the molecular weight markers, the portion of contactin recovered in fractions F3-F4 may correspond to contactin monomers (molecular weight $135 \mathrm{kDa}$ ), whereas contactin detected in the higher density fractions with Caspr is presumably part of a high-molecular-weight complex. In support of this possibility, contactin occasionally could be resolved into two bands - with the upper band predominating in the lighter fractions and the lower isoform in the heavier fractions that overlap with Caspr (data not shown). Similar distribution patterns of Caspr and contactin were observed on sucrose gradients of SML and ZW 3-14 extracts prepared from CNS heavy myelin and homogenates of peripheral nerve, although in these cases contactin appeared to migrate with Caspr more consistently in the higher density fractions (data not shown).

\section{RPTP $\beta C$-Fc perturbs the localization of Caspr in the paranodes}

To examine further the cis interaction between Caspr and contactin, we sequentially incubated DRG neurons with $\beta \mathrm{C}-\mathrm{Fc}$ and a fluorescein-conjugated secondary antibody to human IgG. Cultures were fixed immediately or incubated at $37^{\circ} \mathrm{C}$ to induce clustering and then were double-stained for contactin, Caspr, or the L1 adhesion molecule, as a control. In neurons that were fixed immediately, $\beta \mathrm{C}-\mathrm{Fc}$, contactin, Caspr, and $\mathrm{L} 1$ were all distributed diffusely on the neurites (Fig. 7, $0 \mathrm{hr}$ ). In contrast, $6 \mathrm{hr}$ of incubation with the secondary antibody induced striking clustering of the bound $\beta \mathrm{C}-\mathrm{Fc}$. Of note, contactin and Caspr extensively colocalized with the clustered $\beta \mathrm{C}-\mathrm{Fc}$, whereas L1 remained diffuse (Fig. 7, $6 \mathrm{hr}$ ). These results suggest that most, if not all, of the Caspr is in a cis interaction with contactin.

The strong affinity of $\beta \mathrm{C}-\mathrm{Fc}$ for the Caspr/contactin complex further suggested that it might be useful in analyzing the targeting of this complex to the paranodes. Because $\beta \mathrm{C}-\mathrm{Fc}$ contains the carbonic anhydrase domain of RPTP $\beta$, a putative glial receptor for contactin, it potentially could block interactions of the Caspr/ contactin complex with glial cells and perturb its targeting. To investigate this possibility, we placed neuron-Schwann cell cocultures in myelin-promoting media with or without $\beta \mathrm{C}-\mathrm{Fc}(25$ or 100 $\mu \mathrm{g} / \mathrm{ml})$; the cultures were then maintained for several weeks in the respective media. In the presence of $\beta \mathrm{C}-\mathrm{Fc}$, the cocultures myelinated normally, as indicated by comparable numbers of myelin segments (Fig. 8) and the level of MBP assessed by Western blots of treated and control cultures (data not shown). However, the distribution of Caspr in the treated cultures was perturbed significantly in a dose-dependent manner (Fig. 8; quantified in Table 1). At lower concentrations $(25 \mu \mathrm{g} / \mathrm{ml})$, abnormalities of Caspr staining were observed in $\sim 60 \%$ of the paranodes. The most common finding was the absence of staining at the paranodes. Significant Caspr staining in the nodes of Ranvier and proximal internodes was also much more common in treated than in control cultures. At $100 \mu \mathrm{g} / \mathrm{ml}$, Caspr clustering at the paranodes was blocked completely. Interestingly, Caspr immunoreactivity appeared to be reduced along myelinated internodes even in the treated cultures; one example is located between the arrowheads in Figure 8, $e$ and $f$. These results indicate that binding of $\beta \mathrm{C}-\mathrm{Fc}$ to the complex disrupts its targeting to the paranodes but may not block its downregulation along the internode. These effects are $\beta C$-specific and do not result from the $\mathrm{Fc}$ domain, because normal staining was observed in cultures treated with human $\mathrm{IgG}$ at $100 \mu \mathrm{g} / \mathrm{ml}$ (Fig. $8 a$ ). In initial studies no effect on the distribution of Caspr was observed after treatment with $\mathrm{L} 1-\mathrm{Fc}$, further underscoring the specificity of this effect (data not shown). 

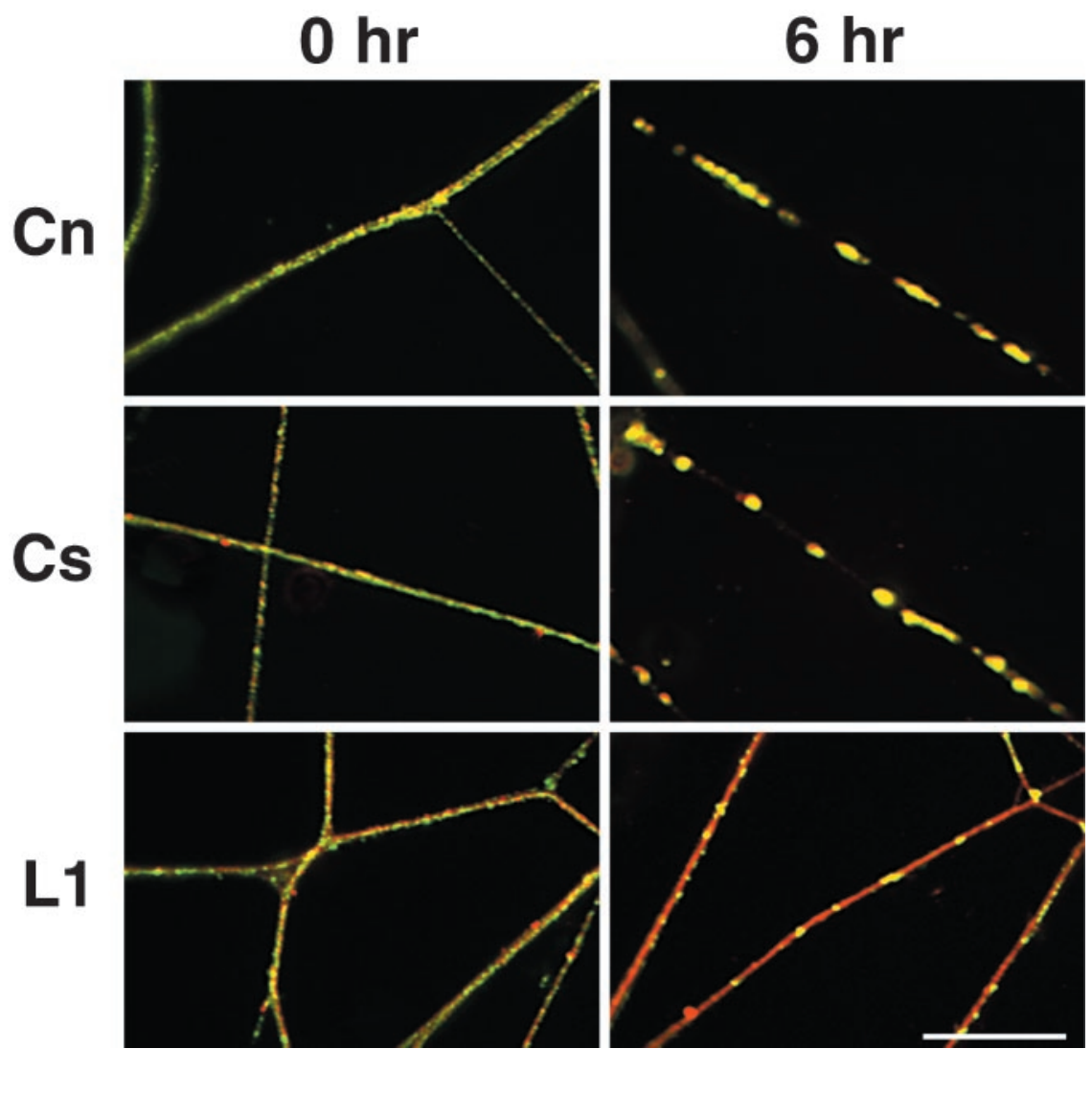

Cs
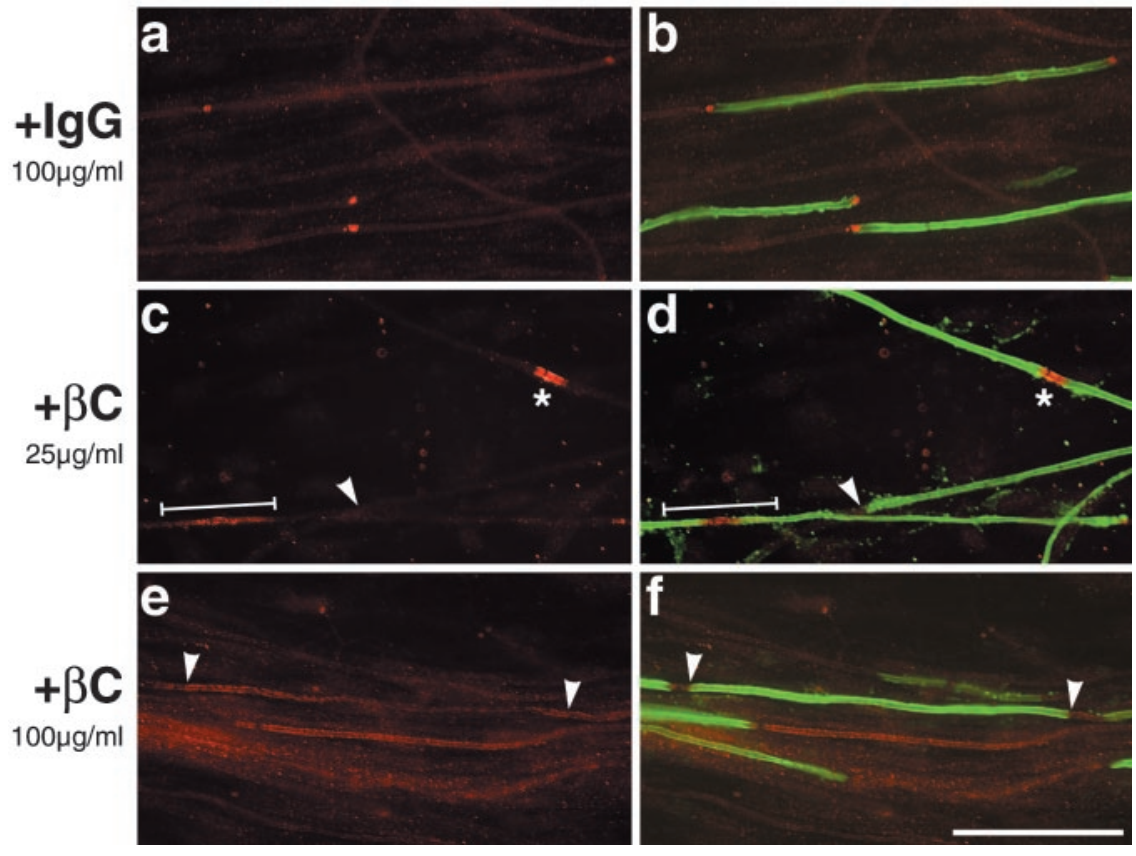

Figure 7. Cocapping of Caspr and contactin on DRG neurons. Cultures of DRG neurons were incubated with $\beta \mathrm{C}-\mathrm{Fc}$ for $1 \mathrm{hr}$ at $4^{\circ} \mathrm{C}$, followed by a $1 \mathrm{hr}$ incubation at $4^{\circ} \mathrm{C}$ with anti-human secondary antibodies $(0$ $h r)$ and an additional $6 \mathrm{hr}$ incubation at $37^{\circ} \mathrm{C}(6 \mathrm{hr})$ to induce clustering; in both instances the cultures were fixed and processed for immunofluorescence. The panels are composed of merged images with $\beta \mathrm{C}-\mathrm{Fc}$ (fluorescein) and contactin, Caspr, and L1 stained with a rhodamine secondary antibody. At $0 \mathrm{hr}$ contactin $(C n)$, Caspr $(C s)$, and L1 (L1) are each distributed diff usely on the neurites. After a $6 \mathrm{hr}$ incubation at $37^{\circ} \mathrm{C}, \beta \mathrm{C}-\mathrm{Fc}$ has induced clustering and cocaps with contactin and Caspr, but not with L1. Scale bar, $10 \mu \mathrm{m}$.

Figure 8. $\quad \beta \mathrm{C}-\mathrm{Fc}$ perturbs Caspr distribution in myelinating cocultures. Cocultures were maintained in myelinating media supplemented with human $\operatorname{IgG}(a$, $b)$ as a control or with media supplemented with either $25 \mu \mathrm{g} / \mathrm{ml}(c, d)$ or $100 \mu \mathrm{g} / \mathrm{ml}(e, f)$ of $\beta C-F c$ and stained for Caspr and MBP. Control cultures (100 $\mu \mathrm{g} / \mathrm{ml} \mathrm{IgG)} \mathrm{displayed} \mathrm{the} \mathrm{normal} \mathrm{paranodal} \mathrm{distribu-}$ tion of Caspr ( $C s$; rhodamine) and normal myelin formation ( $M B P$; fluorescein). $\beta C-F c-t r e a t e d ~ c u l t u r e s$ $(+\beta C)$ myelinate normally but exhibit concentrationdependent abnormalities of Caspr localization, including the absence of Caspr at the paranodes (white arrowheads), Caspr staining at the node (asterisk), and Caspr staining throughout the internode (white line). At the highest concentration, Caspr was absent from essentially all paranodes. Scale bar, $50 \mu \mathrm{m}$.

\section{DISCUSSION}

In previous studies we presented evidence that Caspr and contactin interact laterally in the membrane (Peles et al., 1997) but were able to detect only Caspr in the paranodal junctions (Einheber et al., 1997). Using new reagents, we now report that contactin and Caspr indeed colocalize and form a complex in the paranodes and juxtamesaxon and that treatment with $\beta \mathrm{C}-\mathrm{Fc}$ blocks their redistribution to the paranodes. These results are considered further below.

\section{Contactin and Caspr colocalize in the paranodes and juxtamesaxon, but not in central nodes of Ranvier}

A major finding of this study is that contactin is coexpressed with Caspr in the paranodal and juxtamesaxonal domains. The paranodal junctions have an emerging role in the domain organization of myelinated axons (Peles and Salzer, 2000), whereas the physiological significance of the juxtamesaxon is unknown. It is observed principally in larger nerve fibers in the adult PNS and is rare in 


\begin{tabular}{lccccc}
\hline \multicolumn{6}{l}{ Table 1. Quantitation of the distribution of Caspr in control and $\boldsymbol{\beta C}$-Fc-treated cocultures } \\
& $\begin{array}{l}\text { Total } \\
\text { paranodes }\end{array}$ & $\begin{array}{l}\mathrm{Cs}^{+} \\
\text {paranodes }\end{array}$ & $\begin{array}{l}\mathrm{Cs}^{-} \\
\text {paranodes }\end{array}$ & $\begin{array}{l}\mathrm{Cs}^{+} \\
\text {nodes }\end{array}$ & $\begin{array}{l}\mathrm{Cs}^{+} \\
\text {internodes }\end{array}$ \\
Treatment & 584 & 555 & 21 & 4 & 0 \\
\hline Control & & 95 & 4 & 1 & 0 \\
Percentage of total & 584 & $245^{*}$ & $166^{*}$ & $59^{*}$ & $55^{*}$ \\
$\beta \mathrm{C}-\mathrm{Fc} 25 \mu \mathrm{g} / \mathrm{ml}$ & & 42 & 28 & 20 & 9 \\
Percentage of total & 864 & $32^{*}$ & $747^{*}$ & $19^{*}$ & $47^{*}$ \\
$\beta \mathrm{C}-\mathrm{Fc} 100 \mu \mathrm{g} / \mathrm{ml}$ & 4 & 86 & 4 & 5 \\
Percentage of total & & 4 & & 4
\end{tabular}

The effects of $\beta \mathrm{C}-\mathrm{Fc}$ treatment with 25 or $100 \mu \mathrm{g} / \mathrm{ml}$ on the distribution of Caspr were analyzed. The total numbers of paranodes, identified by their proximity to MBP $(+)$ myelin segments, were counted and then scored for Caspr expression. In control cultures (no treatment) the great majority of paranodes was positive for Caspr immunoreactivity. In $\beta \mathrm{C}-\mathrm{Fc}-$ treated cultures, Caspr was mislocalized or absent from the paranodes in cultures treated with $25 \mu \mathrm{g} / \mathrm{ml}$ and was typically absent from all of the paranodes at $100 \mu \mathrm{g} / \mathrm{ml}$. The distribution of Caspr was perturbed significantly in the treated cultures $\left({ }^{*} p<0.0001 ; \chi^{2}\right.$ Test $)$.

small myelinated nerve fibers in vivo and in vitro (data not shown). The pattern of juxtamesaxonal staining suggests that it is continuous with, and represents an internodal extension of, the inner paranodal spiral (see Fig. 1; also see Arroyo et al., 1999). Interestingly, delayed rectifier potassium channels, which are concentrated in the juxtaparanodal region (Wang et al., 1993; Mi et al., 1995), also flank Caspr in the juxtamesaxon and at sites apposing Schmidt-Lanterman incisures (Arroyo et al., 1999). The Caspr/ contactin complex and flanking potassium channels may correspond to the rows of symmetrical particle aggregates previously observed in freeze-fracture studies of the juxtaparanodal and internodal axolemma (Stolinski et al., 1985). Together, these results provide strong evidence that noncompacted regions of the myelin sheath modulate the distribution of axonal proteins in the paranodes, juxtaparanodes, and internodes.

Unexpectedly, contactin is also present in central, but not peripheral, nodes of Ranvier where it is expressed independently of Caspr. The contactin detected in central nodes is likely to be axonal because it appears to be continuous with the staining observed in the adjacent paranodes (see Fig. 2); however, a contribution from perinodal glial processes cannot be excluded. These results thus provide the first evidence of a difference in the molecular composition of peripheral versus central nodes of Ranvier. The physiological role of contactin in the central nodes is not yet known. Two contactin ligands, tenascin-R and $\operatorname{RPTP} \beta$, also are expressed at the central nodes and have been reported to interact with the sodium channel complex (Srinivasan et al., 1998; Xiao et al., 1999; Ratcliffe et al., 2000). Interestingly, tenascin- $\mathrm{R}$ is required for normal conduction velocity in the optic nerve (Weber et al., 1999) and potentially could modulate conduction velocity and nodal activity via interactions with contactin, sodium channels, or both.

\section{Caspr and contactin are components of a junctional complex}

Consistent with their colocalization, Caspr and contactin form a cis complex in the paranodal junctions. This complex does not assemble as a consequence of myelination but, rather, is preformed. Thus, these proteins cocap efficiently on neurons (see Fig. 7), coprecipitate from neurons and myelinating cultures equivalently (see Fig. 5), and accumulate in the paranodal region with a similar time course (see Fig. 3). It was reported recently that contactin is required for the expression of Caspr/paranodin at the cell surface, indicating that these proteins probably associate within the endomembranous system (Faivre-Sarrailh et al., 2000). These two proteins appear to interact with approximately equivalent stoichiometry on the basis of immunoprecipitation. However, sucrose density gradient analysis suggests that Caspr and contactin associate as a complex of $\sim 550 \mathrm{kDa}$ rather than the $330 \mathrm{kDa}$ expected for a simple contactin-Caspr dimer; these findings suggest that Caspr and contactin may not form a simple heterodimer or that they may associate with other proteins.
Both cytoskeletal and signaling proteins are candidates to interact with Caspr and contactin in the paranodes. The limited solubility of Caspr in Triton X-100 (see Fig. 4) may reflect its association with contactin, which directs it to detergent-insoluble microdomains (Faivre-Sarrailh et al., 2000), or may indicate a cytoskeletal association. Consistent with the latter possibility, ultrastructural studies suggest the presence of a specialized cytoskeleton subjacent to the paranodal junctions (Ichimura and Ellisman, 1991). In addition, the cytoplasmic domain of Caspr is homologous to the region of glycophorin that binds to band 4.1, a component of the erythrocyte cytoskeleton. A potential interaction between the cytoplasmic domain of Caspr and band 4.1 was reported by Menegoz et al. (1997), although its physiological relevance is unclear at present. Several signaling molecules are also candidates to interact with the proline-rich domain of the cytoplasmic segment of Caspr, including PLC $\gamma$, src, fyn, and the p85 subunit of PI-3 kinase (Peles et al., 1997). In preliminary studies (J. Rios, C. V. MelendezVasquez, and J. Salzer, unpublished observations) we have been unable to confirm a paranodal localization for any of these proteins or for $\mathrm{PTP} \alpha$, which was reported recently to associate with contactin (Zeng et al., 1999).

\section{Two forms of contactin differentially associate with Caspr}

We and others previously reported the existence of two contactin isoforms in the nervous system that are distinguishable by their molecular weight and sensitivity to PI-PLC (Rosen et al., 1992; Olive et al., 1995). Immunoprecipitation results in this study (see Fig. 5) indicate that Caspr specifically associates with the lowermolecular-weight PI-PLC-resistant form of contactin. In agreement, the lower-molecular-weight isoform preferentially overlaps with Caspr on sucrose gradients, coextracts with Caspr from sciatic nerve, and specifically fractionates with PNS myelin. Together these results indicate that this isoform is complexed with Caspr in the paranodes and juxtamesaxon. The differences in molecular weight between the two contactin isoforms reflect differences in the extent of glycosylation (see Fig. $5 B$ ). Because contactin is likely to associate with Caspr in the ER (Faivre-Sarrailh et al., 2000), subsequent processing of its carbohydrates in the Golgi could be affected. In potential agreement, F11, the chicken homolog of contactin, is a mixture of two molecular species that contain either complex or high mannose-type carbohydrates (Wolff et al., 1987). The differential sensitivity of these contactin isoforms to PI-PLC is also likely to reflect whether or not they are associated with Caspr; either the lower contactin band is cleaved but remains attached to the cell via its interaction with Caspr or, alternatively, it is insensitive to PI-PLC. In the latter case, resistance to cleavage could reflect steric hindrance because of its association with Caspr, although modifications of its GPI anchor that render it PI-PLCinsensitive (Toutant et al., 1990) are also a possibility.

The expression of two neuronal forms of contactin that differ in their association with Caspr has important functional implications. 
Contactin regulates neurite outgrowth, fasciculation, and axonal guidance (Faivre-Sarrailh and Rougon, 1997), and Caspr has been proposed to mediate the transmembrane signaling of the complex (Peles et al., 1997). These contactin isoforms would have different functions in this model because the nonassociated form might bind to a ligand without signaling in contrast to the Caspr-associated form of contactin. The association of Caspr also may regulate the interactions of contactin with extracellular ligands (see below) and its targeting to specific axonal domains. Of note, contactin that is complexed with Caspr is localized to the paranodes of the optic nerve, whereas free contactin is present in the adjacent nodes of Ranvier (see Fig. 2). Whether this differential localization reflects unique interactions conferred on contactin via its association with Caspr is of significant interest for further investigation.

\section{Targeting of the Caspr/contactin complex}

We have shown that $\beta \mathrm{C}-\mathrm{Fc}$ binds to and completely blocks the targeting of the Caspr/contactin complex to the paranodes (see Fig. 8). Initial studies reveal significant abnormalities in this region, including loss of normal septae, whereas compact myelin is unaffected (J. Rios, S. Einheber, and J. Salzer, unpublished observations). Further studies are in progress.

A likely mechanism by which the binding of $\beta \mathrm{C}-\mathrm{Fc}$ interferes with targeting is by blocking interactions of this complex with presumptive glial receptors. The glial receptor or receptors for Caspr and contactin that promote their localization have not been identified; indeed, it is not known whether these proteins have independent ligands or are recognized as a complex. Contactin has a number of known ligands, including itself (Gennarini et al., 1991), the adhesion molecules Nr-CAM, Ng-CAM, and neurofascin (Brümmendorf et al., 1993; Morales et al., 1993; Sakurai et al., 1997; Volkmer et al., 1998), tenascin (Zisch et al., 1992; Pesheva et al., 1993), and RPTP $\beta$ (Peles et al., 1995). We have detected expression of RPTP $\beta$ mRNA by Schwann cells but have not observed a specific localization at the paranodes in either the CNS or PNS (S. Scherer, J. Rios, J. Salzer, unpublished observations). In contrast, the $155 \mathrm{kDa}$ neurofascin isoform is enriched in the paranodes (Davis et al., 1996) and recently was identified as a glial component of the paranodal junctions (Tait et al., 2000); it is therefore a candidate to bind directly or indirectly to contactin in this site. Essentially nothing is known about the ligand or ligands for Caspr. The extracellular segment of Caspr contains a discoidin domain and neurexin repeats, each of which displays homology to lectin-binding domains (Rudenko et al., 1999). This homology and the significant abnormalities in the paranodal region of mice deficient in galactocerebroside (Dupree et al., 1999) raise the possibility that this myelin glycolipid is itself a ligand. An alternate possibility is that other abnormalities in the myelin sheaths of these mice indirectly affect paranodal interactions (Popko, 2000).

In summary, we have shown that Caspr and a subpopulation of contactin form a complex on neurons that is targeted to the paranodal junctions, potentially via extracellular interactions. Identification of other junctional components, including the glial ligands for Caspr and contactin, and analysis of contactin (Berglund et al., 1999) and Caspr null mice also will further define the role of these proteins in paranodal interactions.

\section{REFERENCES}

Arroyo EJ, Scherer SS (2000) On the molecular architecture of myelinated fibers. Histochem Cell Biol 113:1-18.

Arroyo EJ, Xu YT, Zhou L, Messing A, Peles E, Chiu SY, Scherer SS (1999) Myelinating Schwann cells determine the internodal localization of Kv1.1, Kv1.2, Kv 32 , and Caspr. J Neurocytol 28:333-347.

Berglund EO, Murai KK, Fredette B, Sekerkova G, Marturano B, Weber L, Mugnaini E, Ranscht B (1999) Ataxia and abnormal cerebellar microorganization in mice with ablated contactin gene expression. Neuron 24:739-750.

Bosio A, Bussow H, Adam J, Stoffel W (1998) Galactosphingolipids and axono-glial interaction in myelin of the central nervous system. Cell Tissue Res 292:199-210.

Brümmendorf T, Wolff JM, Frank R, Rathjen F (1989) Neural cell recognition molecule F11: homology with fibronectin type III and immunoglobulin type C domains. Neuron 2:1351-1361.
Brümmendorf T, Hubert M, Treubert U, Leuschner R, Tárnok A, Rathjen FG (1993) The axonal recognition molecule F11 is a multifunctional protein: specific domains mediate interactions with Ng-CAM and restrictin. Neuron 10:711-727.

Coetzee T, Fujita N, Dupree J, Shi R, Blight A, Suzuki K, Popko B (1996) Myelination in the absence of galactocerebroside and sulfatide: normal structure with abnormal function and regional instability. Cell 86:209-219.

Davis JQ, Lambert S, Bennett V (1996) Molecular composition of the node of Ranvier: identification of ankyrin-binding cell adhesion molecules neurofascin $\left(\right.$ mucin $^{+} /$third FN III domain $^{-}$) and NrCAM at nodal axon segments. J Cell Biol 135:1355-1367.

Dupree JL, Girault JA, Popko B (1999) Axo-glial interactions regulate the localization of axonal paranodal proteins. J Cell Biol 147:1145-1152.

Einheber S, Zanazzi G, Ching W, Scherer S, Milner TA, Peles E, Salzer JL (1997) The axonal membrane protein Caspr, a homologue of neurexin $\mathrm{IV}$, is a component of the septate-like paranodal junctions that assemble during myelination. J Cell Biol 139:1495-1506.

Faivre-Sarrailh C, Rougon G (1997) Axonal molecules of the immunoglobulin superfamily bearing a GPI anchor: their role in controlling neurite outgrowth. Mol Cell Neurosci 9:109-115.

Faivre-Sarrailh C, Gauthier F, Denisenko-Nehrbass N, Le Bivic A, Rougon G, Girault JA (2000) The glycosylphosphatidyl inositol-anchored adhesion molecule F3/contactin is required for surface transport of paranodin/contactin-associated protein (Caspr). J Cell Biol 149:491-502. Friedlander DR, Milev P, Karthikeyan L, Margolis RK, Margolis RU, Grumet M (1994) The neuronal chondroitin sulfate proteoglycan neurocan binds to the neural cell adhesion molecules Ng-CAM/L1/NILE and N-CAM, and inhibits neuronal adhesion and neurite outgrowth. J Cell Biol 125:669-680.

Gennarini G, Rougon G, Vitiello F, Corsi P, Di Benedetta C, Goridis C (1989) Identification and cDNA cloning of a new member of the L2/ HNK-1 family of neural surface glycoproteins. J Neurosci Res 22:1-12.

Gennarini G, Durbec P, Boned A, Rougon G, Goridis C (1991) Transfected F3/F11 neuronal cell surface protein mediates intercellular adhesion and promotes neurite outgrowth. Neuron 6:595-606.

Greenfield S, Brostoff S, Eylar EH, Morell P (1973) Protein composition of myelin of the peripheral nervous system. J Neurochem 20:1207-1216.

Ichimura T, Ellisman MH (1991) Three-dimensional fine structure of cytoskeletal-membrane interactions at nodes of Ranvier. J Neurocytol 20:667-681.

Koch T, Brugger T, Bach A, Gennarini G, Trotter J (1997) Expression of the immunoglobulin superfamily cell adhesion molecule F3 by oligodendrocyte-lineage cells. Glia 19:199-212.

Martin RG, Ames BN (1961) A method for determining the sedimentation behavior of enzymes: application to protein mixtures. J Biol Chem 236:1372-1379.

Matthieu JM, Quarles RH, Brady RO, Webster HdF (1973) Variation of proteins, enzyme markers, and gangliosides in myelin subfractions. Biochim Biophys Acta 329:305-317.

Melendez-Vasquez CV, Einheber S, Peles E, Salzer JL (1999) Isolation of a high molecular weight complex from the paranodal junctions: evidence for an association of contactin and Caspr. Soc Neurosci Abstr 25:999.

Menegoz M, Gaspar P, Le Bert M, Galvez T, Burgaya F, Palfrey C, Ezan P, Arnos F, Girault JA (1997) Paranodin, a glycoprotein of neuronal paranodal membranes. Neuron 19:319-331.

Mi H, Deerinck TJ, Ellisman MH, Schwarz TL (1995) Differential distribution of closely related potassium channels in rat Schwann cells. J Neurosci 15:3761-3774.

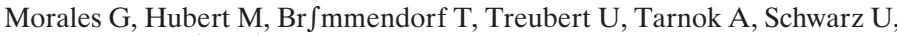
Rathjen FG (1993) Induction of axonal growth by heterophilic interactions between the cell surface recognition proteins F11 and Nr-CAM/ Bravo. Neuron 11:1113-1122.

Norton W, Cammer W (1984) Isolation and characterization of myelin. In: Myelin (Morell P, ed), pp 147-195. New York: Plenum.

Norton WT, Poduslo SE (1973) Myelination in rat brain: method of myelin isolation. J Neurochem 21:749-757.

Olive S, Dubois C, Schachner M, Rougon G (1995) The F3 neuronal glycosylphosphatidylinositol-linked molecule is localized to glycolipidenriched membrane subdomains and interacts with L1 and fyn kinase in cerebellum. J Neurochem 65:2307-2317.

Pedraza L, Owens GC, Green LAD, Salzer JL (1990) The myelinassociated glycoproteins: membrane disposition, evidence of a novel disulfide linkage between immunoglobulin-like domains, and posttranslational palmitylation. J Cell Biol 111:2651-2661.

Peles E, Salzer JL (2000) Molecular domains of myelinated axons. Curr Opin Neurobiol 10:558-565.

Peles E, Nativ M, Campbell PL, Sakurai T, Martinez R, Lev S, Clary DO, Schilling J, Barnea G, Plowman GD (1995) The carbonic anhydrase domain of receptor tyrosine phosphatase $\beta$ is a functional ligand for the axonal cell recognition molecule contactin. Cell 82:251-260.

Peles E, Nativ M, Lustig M, Grumet M, Schilling J, Martinez R, Plowman GD, Schlessinger J (1997) Identification of a novel contactin-associated transmembrane receptor with multiple domains implicated in proteinprotein interactions. EMBO J 16:978-988.

Pesheva P, Gennarini G, Goridis C, Schachner M (1993) The F3/F11 cell 
adhesion molecule mediates the repulsion of neurons by the extracellular matrix glycoprotein J1-160/180. Neuron 10:69-82.

Peters A, Palay SL, Webster HdF (1991) The fine structure of the nervous system. New York: Oxford UP.

Popko B (2000) Myelin galactolipids: mediators of axon-glial interactions? Glia 29:149-153.

Ranscht B (1988) Sequence of contactin, a $130 \mathrm{kDa}$ glycoprotein concentrated in areas of interneuronal contact, defines a new member of the immunoglobulin supergene family in the nervous system. J Cell Biol 107:1561-1573.

Ratcliffe CF, Qu Y, McCormick KA, Tibbs VC, Dixon JE, Scheuer T, Catterall WA (2000) A sodium channel signaling complex: modulation by associated receptor protein tyrosine phosphatase beta. Nat Neurosci 3:437-444.

Reid RA, Bronson DD, Young KM, Hemperly JJ (1994) Identification and characterization of the human cell adhesion molecule contactin. Brain Res Mol Brain Res 21:1-8.

Rios JC, Lustig M, Grumet M, Gollan L, Peles E, Hemperly JJ, Salzer JL (1999) Caspr and contactin colocalize in the paranodal and internodal membranes of myelinated axons. Soc Neurosci Abstr 25:999.

Rosen CL, Lisanti MP, Salzer JL (1992) Expression of unique sets of GPI-linked proteins by different primary neurons in vitro. J Cell Biol 117:617-627.

Rosenbluth J (1995) Glial membranes and axoglial junctions. In: Neuroglia (Kettenmann H, Ransom BR, eds), pp 613-633. New York: Oxford UP.

Rudenko G, Nguyen T, Chelliah Y, Sudhof TC, Deisenhofer J (1999) The structure of the ligand-binding domain of neurexin I $\beta$ : regulation of LNS domain function by alternative splicing. Cell 99:93-101.

Sakurai T, Lustig M, Nativ M, Hemperly JJ, Schlessinger J, Peles E, Grumet M (1997) Induction of neurite outgrowth through contactin and $\mathrm{Nr}-\mathrm{CAM}$ by extracellular regions of glial receptor tyrosine phosphatase beta. J Cell Biol 136:907-918.

Salzer JL (1997) Clustering sodium channels at the node of Ranvier: close encounters of the axon-glia kind. Neuron 18:843-846.

Srinivasan J, Schachner M, Catterall WA (1998) Interaction of voltagegated sodium channels with the extracellular matrix molecules tenascin- $\mathrm{C}$ and tenascin-R. Proc Natl Acad Sci USA 95:15753-15757.

Stolinski C, Breathnach AS, Thomas PK, Gabriel G, King RH (1985)
Distribution of particle aggregates in the internodal axolemma and adaxonal Schwann cell membrane of rodent peripheral nerve. J Neurol Sci 67:213-222.

Tait S, Gunn-Moore F, Collinson JM, Huang J, Lubetzki C, Pedraza L, Sherman DL, Colman DR, Brophy PJ (2000) An oligodendrocyte cell adhesion molecule at the site of assembly of the paranodal axo-glial junction. J Cell Biol 150:657-666.

Tao-Cheng JH, Rosenbluth J (1983) Axolemmal differentiation in myelinated fibers of rat peripheral nerves. Brain Res 285:251-263.

Toutant J-P, Richards MK, Krall JA, Rosenberry TL (1990) Molecular forms of acetylcholinesterase in two sublines of human erythroleukemia K562 cells: sensitivity or resistance to phosphatidylinositol-specific phospholipase C and biosynthesis. Eur J Biochem 187:31-38.

Volkmer H, Zacharias U, Norenberg U, Rathjen FG (1998) Dissection of complex molecular interactions of neurofascin with axonin-1, F11, and tenascin-R, which promote attachment and neurite formation of tectal cells. J Cell Biol 142:1083-1093.

Wang H, Kunkel DD, Martin TM, Schwartzkroin PA, Tempel BL (1993) Heteromultimeric $\mathrm{K}^{+}$channels in terminal and juxtaparanodal regions of neurons. Nature 365:75-79.

Weber P, Bartsch U, Rasband MN, Czaniera R, Lang Y, Bluethmann H, Margolis RU, Levinson SR, Shrager P, Montag D, Schachner M (1999) Mice deficient for tenascin-R display alterations of the extracellular matrix and decreased axonal conduction velocities in the CNS. J Neurosci 19:4245-4262.

Wolff JM, Rathjen FG, Frank R, Roth S (1987) Biochemical characterization of polypeptide components involved in neurite fasciculation and elongation. Eur J Biochem 168:551-561.

Xiao ZC, Ragsdale DS, Malhotra JD, Mattei LN, Braun PE, Schachner M, Isom LL (1999) Tenascin-R is a functional modulator of sodium channel $\beta$-subunits. J Biol Chem 274:26511-26517.

Zeng L, D'Alessandri L, Kalousek MB, Vaughan L, Pallen CJ (1999) Protein tyrosine phosphatase alpha (PTP $\alpha$ ) and contactin form a novel neuronal receptor complex linked to the intracellular tyrosine kinase fyn. J Cell Biol 147:707-714.

Zisch AH, D'Alessandri L, Falchetto R, Winterhalter KH, Ranscht B, Vaughan L (1992) Neuronal cell adhesion molecule contactin/F11 binds to tenascin via its immunoglobulin-like domains. J Cell Biol 119:203-213. 